\title{
Heparin Derivative SST0001
}

National Cancer Institute

\section{Source}

National Cancer Institute. Heparin Derivative SST0001. NCI Thesaurus. Code C104412.

An $\mathrm{N}$-acetylated, glycol-split form of heparin that is devoid of anticoagulant activity and is an inhibitor of heparanase with antineoplastic and antiangiogenic activities. Upon subcutaneous administration, heparin derivative SST 0001 inhibits the activity of heparanase. This prevents the heparanase-mediated cleavage of heparan sulfate (HS) proteoglycans on cell surfaces and within the extracellular matrix. In addition, this agent prevents the heparanase-induced production of a number of angiogenic growth factors, including matrix metalloproteinase-9, hepatocyte growth factor and vascular endothelial growth factor. Altogether, this leads to an inhibition of both tumor cell growth and ang iogenesis. Heparanase, an enzyme that is responsible for the proteolytic cleavage of proteoglycans, is upregulated in a variety of tumor cell types and promotes tumor cell growth; it plays a key role in tumor cell invasion, metastasis and angiogenesis. 